\title{
Configurações
}

Revista de sociologia

$24 \mid 2019$

Imaginar "futuros" do trabalho, contextos e vivências subjetivas

\section{LinkedIn e o Capital Social gerado na busca de emprego}

LinkedIn and the Social Capital generated in job search

LinkedIn et le Capital Social généré lors de la recherche d'emploi

\section{Manuel Pereira Soares}

\section{(2) OpenEdition}

\section{Journals}

\section{Edição electrónica}

URL: http://journals.openedition.org/configuracoes/7689

DOI: 10.4000/configuracoes.7689

ISSN: 2182-7419

\section{Editora}

Centro de Investigação em Ciências Sociais

\section{Edição impressa}

Paginação: 45-60

ISSN: 1646-5075

\section{Refêrencia eletrónica}

Manuel Pereira Soares, "Linkedln e o Capital Social gerado na busca de emprego », Configurações [Online], 24 | 2019, posto online no dia 18 dezembro 2019, consultado o 19 dezembro 2019. URL : http://journals.openedition.org/configuracoes/7689; DOI : 10.4000/configuracoes.7689 
Soares, Manuel Pereira - Linkedln e o Capital Social gerado na busca de emprego. Configurações, vol. 24, 2019, pp. 45-60.

\title{
Linkedln e o Capital Social gerado na busca de emprego
}

MANUEL PEREIRA SOARES *

Faculdade de Economia da Universidade de Coimbra

\section{Resumo}

Neste texto procura perceber-se o capital social gerado pelas redes sociais na busca de emprego, incidindo a análise no LinkedIn. Partindo do texto de Mark Granovetter A força dos laços fracos, faz-se uma análise crítica às ideias deste investigador. Recorrendo à rede de contactos de uma página do LinkedIn, pretende-se conhecer qual a real vantagem dos laços fracos para o capital social na busca de emprego. O resultado do exercício leva a questionar a mais-valia desse contributo, dado grande parte dessas ligações serem constituídas por indivíduos da mesma área profissional e, portanto, concorrentes.

Palavras-chave: capital social; LinkedIn; redes sociais; laços sociais; procura de emprego.

\begin{abstract}
LinkedIn and the Social Capital generated in job search

In this text we intend to understand the social capital generated by social networks regarding the search for a new job, focusing specifically on a digital social network for professionals: LinkedIn. Starting with Mark Granovetter's text The Strength of Weak Ties, we seek to understand the extent to which the ideas of this investigator can be applied to this social network, exploring some of the weaknesses pointed out in this theory.
\end{abstract}

Keywords: social capital; LinkedIn; social networks; social ties; job search.

^E-mail: manuelpsoares@gmail.com 


\section{Resumé \\ LinkedIn et le Capital Social généré lors de la recherche d'emploi}

Dans ce texte, nous cherchons à comprendre le capital social généré par les réseaux sociaux lors de la recherche d'emploi, cette analyse étant centrée sur LinkedIn, un réseau social pour professionnels. À partir du texte de Mark Granovetter La force des liens faibles, nous cherchons à comprendre dans quelle mesure les idées de ce chercheur peuvent s'appliquer à ce réseau social, en exploitant quelques fragilités mises en évidence dans sa théorie.

Mots-clés: capital social; LinkedIn; réseaux sociaux; liens sociaux; recherche d'emploi.

\section{Introdução}

As redes sociais, principalmente na sua forma digital, têm sido apresentadas e discutidas como sendo o meio mais eficaz e poderoso para colocar em comunicação constante e global milhões de pessoas, explorando-se cada vez mais a ideia de que quem não está nas redes não existe. No entanto, estas permitem ser analisadas de forma bem mais lata do que apenas centrada na sua forma virtual, sendo que, em todos os casos, podem, e assumem, um papel importante no providenciar de recursos e informações que possam beneficiar o indivíduo ou o grupo que as compõe. Entramos, então, no campo do capital social que pode ser gerado pelas redes (digitais ou não) e na maior ou menor importância, ou na maior ou menor facilidade, que oferecem no provir de informações e recursos para benefício dos seus membros, tendo em conta que as tecnologias de informação constituem atualmente um dos meios privilegiados que as pessoas utilizam para procurar aumentar o capital social, uma vez que permitem que elas se conectem a outras fora dos seus grupos, formando comunidades de interesses (Ellison, Steinfield \& Lampe, 2007).

Partindo de um texto de Mark Granovetter (1973), é propósito deste trabalho tentar perceber em que medida os laços fracos, que parecem estar presentes em maioria nas redes virtuais, como sucede com o LinkedIn (Utz, 2016), podem assumir uma função de facultadores de informação relevante para a busca de emprego. Recorrendo à nossa própria página do LinkedIn, fazendo a análise das suas conexões, é-nos possível apurar qual a força desses laços e se eles podem, ou não, cumprir um dos propósitos desta rede social: constituir-se como um meio de acesso a informação sobre novas oportunidades de emprego. Além dos habituais laços fortes e fracos, a noção de laço latente (Haythornthwaite, 2011) parece assumir especial relevância nesta rede social, apresentando-se ele como uma das mais-valias das comunidades virtuais, uma vez que permite proporcionar novos contactos profissionais que, de outra forma, seriam muito difíceis de conseguir. 
Inicialmente explorar-se-á os conceitos de rede social e capital social para, de seguida, fazer uma breve descrição do LinkedIn, discutindo, por fim, a problemática dos laços fortes e fracos de Granovetter, destacando a mais-valia que a ideia de laços latentes pode constituir para o aumento de capital social por via das redes sociais. Analisaremos os nossos contactos e procuraremos colocar em diálogo as ideias de capital social e de laços, no sentido de perceber qual é, afinal, a força dos laços fracos a que alude Granovetter.

\section{Rede Social e Capital Social}

Procurar definir rede social seria matéria para um outro texto que extravasa o âmbito deste. Numa definição minimalista, rede social poderá ser entendida como um conjunto de dois elementos compostos por atores (que podem ser pessoas, instituições ou grupos), de um lado, e suas conexões, do outro (Recuero, 2006). A rede social também pode ser entendida como sendo as relações entre pessoas que, de uma forma ou de outra, assumem importância para um dos elementos da rede (Phulari et al., 2010). A rede social será, então, composta por laços (relações) que podem ser considerados como sendo fortes ou fracos (Granovetter, 1973), dependendo da quantidade e qualidade do contacto que mantêm entre si (relações de amizade, parentesco, vizinhança ou relações profissionais). Uma mesma rede social poderá, contudo, ser composta só de laços fortes, fracos ou de uma mistura dos dois, sendo certo que a tipologia dos laços presentes poderá determinar os diferentes objetivos da rede. No caso das redes virtuais, há uma tendência para elas se organizarem de acordo com o propósito de cada uma delas. O Facebook, por exemplo, a mais conhecida e mediática rede social da atualidade, consiste em conectar milhares de pessoas mediante a aceitação, ou não, de um dos membros de novo convite de associação que lhe é feito. As conexões poderão, portanto, ser compostas por familiares desse elemento, amigos, conhecidos ou por perfeitos desconhecidos, sendo uma rede que valoriza a informação sobre os gostos, hobbies e demais informação de caráter pessoal do utilizador, tendo como missão “dar às pessoas o poder de construir comunidade e aproximar o mundo" (tradução nossa) ${ }^{1}$. Podem, depois, criar-se grupos específicos dentro da rede, onde a restrição de acesso, $a$ priori, será maior, pois a criação de um determinado grupo (de estudantes de Sociologia, por exemplo) implica que, à partida, só pessoas que reúnam essas características possam integrá-lo. As redes sociais, especialmente as que existem na internet, permitem aos seus utilizadores serem construídas mediante convites que são enviados a outros participantes, pelo que não é fácil aferir o

1 "Give people the power to build community and bring the world closer together" no original, obtida em https://pt-pt.facebook.com/pg/facebook/about/?ref=page_internal, consultada em 25 Junho 2019. 
grau de ligação existente entre os elementos da rede e o seu titular, uma vez que ela permite associar tanto conexões próximas como de desconhecidos (Phulari et al., 2010).

O LinkedIn baseia-se no princípio da identificação, pois, sendo uma rede social virtual para profissionais, é suposto que o interesse em a integrar seja norteado pela questão profissional, quer seja porque pretende conhecer mais pessoas da sua área profissional, quer porque pretende aumentar a sua rede de conhecimentos noutras áreas de interesse para futuro alargar de horizontes e perspetivas profissionais. De qualquer forma, quem se inscreve nesta rede não o faz com o propósito do Facebook, ou seja, não tem como objetivo fazer amigos, mas, sim, alargar a sua teia de contactos profissionais, uma vez que, do ponto de vista económico, uma das razões que confere um valor decisivo aos laços pessoais é o facto de eles permitirem o acesso a informação privilegiada e a recursos que podem, a qualquer momento, ser mobilizados para gerar benefícios próprios, daí o investimento pessoal que é feito nas redes (Pena-López \& Sánchez-Santos, 2017).

As redes sociais virtuais existem, portanto, com propósitos diferentes e, embora a ideia subjacente a todas elas seja a de construir redes, o capital social conseguido assume significados diferentes, dependendo do fim para o qual o queremos direcionar.

Pierre Bourdieu afirma que o capital social é:

o agregado dos recursos reais ou potenciais que estão associados a uma rede durável de relações mais ou menos institucionalizadas de conhecimento mútuo e de reconhecimento - ou, em outras palavras, à participação num grupo - que fornece a cada um dos seus membros o apoio do capital coletivo, uma "credencial” que lhes confere o direito a crédito, nos vários sentidos da palavra (Bourdieu, 1986: 21, tradução nossa).

Paul Adler e Seok-Woo (2002: 17-18) definem capital social como sendo "a boa-vontade que pode ser gerada através das relações sociais e que pode ser mobilizada para facilitar ações" (tradução nossa), entendendo-se essa boa-vontade como a simpatia, a confiança e o perdão dos outros para connosco, o que a torna um recurso valioso. Nan Lin (2004) define capital social como sendo o "investimento feito nas relações sociais com retornos expectados no mercado". Para Putnam o capital social "refere-se às conexões e tem como elementos a reciprocidade e a confiança”, como recorda Raquel Recuero (2005:3). O capital social gerado pelas redes pode assumir um papel importante para o acesso a determinados recursos, como sejam a habitação, o emprego ou os cuidados de saúde (Portugal, 2006), especialmente se atentarmos que a quantidade do capital social de uma pessoa está relacionada não apenas com o tamanho da sua rede de contactos, mas também com os tipos de capital (económico, cultural 
ou simbólico) que essas ligações possuem (Bourdieu, 1986: 21). Em termos profissionais, o capital social permite tanto influenciar positivamente a carreira como ajudar os trabalhadores a encontrar emprego (Adler \& Kwon, 2002: 17). Quanto maior o capital social, maior o compromisso com a comunidade e a capacidade para a mobilização coletiva, uma vez que o "capital social permite às pessoas obterem benefícios de outros membros da sua rede" (Ellison et al., 2007: 1145). Daí a ênfase que os sites de recrutamento, como o LinkedIn, por exemplo, colocam no networking, incentivando os utilizadores a conectarem-se a "pessoas que podem ajudar" (LinkedIn, 2019). Os indivíduos investem nas suas redes como forma de gerar benefícios (Lin, 2004: 19).

Independentemente da definição do autor que mais consensos acolhe em determinada altura, uma coisa parece certa: o capital social parece pressupor sempre uma tentativa de capitalização das relações de confiança e de conhecimento da rede que o indivíduo pode procurar transformar, se assim entender, em benefícios para si próprio ou para o grupo, pelo que existem investimentos estratégicos nessa rede, para que daí se possam retirar benefícios a curto ou longo prazo (Bourdieu, 1986: 22). As redes sociais profissionais assumem, portanto, um papel importante nesse jogo, porquanto elas permitem aos utilizadores o acesso a laços fracos em campos relevantes para o seu interesse profissional e que lhe providenciarão informação útil (Utz, 2016: 2688).

\section{0 LinkedIn}

Fundado em 2003 nos Estados Unidos da América, o LinkedIn é uma rede social virtual para profissionais que conta actualmente com mais de 562 milhões de membros em mais de 200 países (LinkedIn, 2019), sendo uma das redes mais conhecidas e utilizadas.

A missão do LinkedIn é "conectar profissionais do mundo todo, tornando-os mais produtivos e bem-sucedidos" (LinkedIn, 2019). O paradigma de recrutamento tem mudado desde o surgimento das tecnologias de informação, assumindo as redes sociais virtuais profissionais um papel cada vez mais importante para esta ação (Jobvite, 2019), embora sejam utilizadas como um complemento às formas de recrutamento tradicionais, e não como sua substituição (Gomes, 2011; Pedroso, 2016). Em 2018, o LinkedIn colheu a preferência de $77 \%$ dos profissionais de recrutamento, número que, contudo, ficou bastante abaixo da percentagem obtida no ano anterior, que foi de $92 \%$ (Jobvite, 2019), apresentando, ainda assim, um nível de utilização muito considerável.

Nos últimos anos têm-se realizado diversos estudos que visam medir o impacto das redes sociais virtuais na busca de emprego, assentando, contudo, esses trabalhos na abordagem do ponto de vista do recrutador (Girard \& Fallery, 2011; Gomes, 2011; Koch, Gerber \& Klerk, 2018; Pedroso, 2016). 
Falta, em nosso entender, realizar trabalho que incida sobre as potencialidades que estas redes possam oferecer no provir de informação relevante que os utilizadores obtêm por estarem conectados a essas redes. Nesse sentido, este trabalho visa aferir o impacto que o LinkedIn tem no capital social dos seus membros quando buscam uma oportunidade de emprego. Esta possibilidade é, aliás, apresentada como uma das funcionalidades centrais do LinkedIn, ao ponto de, em 2005, ter sido disponibilizado um serviço no site intitulado LinkedIn Jobs que, como o nome indica, se dedica especificamente a facilitar o contacto entre empregadores e potenciais empregados. Posteriormente, foi sofrendo evoluções e atualmente disponibiliza uma miríade de serviços que visa ir ao encontro quer das necessidades dos empregadores, quer daqueles que buscam oportunidades de emprego ${ }^{2}$.

O LinkedIn assenta, portanto, num serviço de subscrição gratuito em que cada membro, mediante um registo no site, tem a possibilidade de se conectar a milhares de outros membros da sua área profissional, ou outra que entenda, construindo uma rede de contactos de carácter global cuja extensão o próprio poderá gerir mediante a aceitação ou não de novos membros na sua conta pessoal e enviando ele próprio pedidos de conexão a outros membros. A subscrição gratuita do site permite disponibilizar online um perfil profissional e construir uma rede de contactos. Existe um conjunto de funcionalidades e opções que obriga a subscrições de serviços pagos, o que permite aumentar a visibilidade do membro e, também, aceder a informação mais detalhada que lhe possa interessar para certos domínios. Uma das possibilidades que o LinkedIn oferece, por exemplo, é informar o membro de quantas vezes o seu perfil foi visitado e o seu nome foi pesquisado por outros utilizadores num determinado período. No entanto, a identificação do utilizador, ou empresa, que pesquisou essa informação, não é, por norma, revelado, pelo que o membro terá de optar por se inscrever numa conta Premium para poder aceder a essa, e outra, informação mais detalhada. Depreende-se que o LinkedIn tem uma vertente comercial muito forte, e o seu sucesso não se deve apenas por ser um sítio gratuito de conectividade entre pessoas (como o Facebook, por exemplo), mas pelo facto de ter como objetivo facultar o acesso a serviços para profissionais cuja qualidade e quantidade de recursos disponibilizados depende do pagamento de mensalidades ao site. Em qualquer caso, pago ou não, todas as contas do LinkedIn permitem que o utilizador parametrize o seu perfil de forma a ser visível ao máximo de utilizadores. Ao acrescentar alguém à sua lista de contactos, o utilizador tem, de imediato, acesso à lista de contactos desse membro, desde que este assim tenha configurado a sua rede, o que permite que ela aumente a cada novo elemento que lhe é acrescentado. 


\section{Qual a força dos laços fracos de Granovetter?}

Quando Mark Granovetter publicou, em 1973, o seu texto The Strength of Weak Ties (Granovetter, 1973) procurou demonstrar que é através dos laços fracos que mais facilmente se conseguem informações relevantes para oportunidades de emprego. Importa entender, em primeiro lugar, o que Granovetter entende como sendo a força do laço. Traduzindo as suas palavras:

A força de um laço é uma combinação (provavelmente linear) da quantidade de tempo, intensidade emocional, intimidade (confiança mútua) e dos serviços recíprocos que o caraterizam (Granovetter, 1973:1361).

Entende-se, então, que existam dois tipos de laços - fortes e fracos - cuja tipificação dependerá da força e da intensidade da relação existente. Os conhecidos e colegas serão as ligações mais abundantes e constituirão os laços fracos. Aqui se podem encontrar, por exemplo, os colegas de trabalho, com quem mantemos um contacto estritamente profissional, e os vizinhos e conhecidos, com quem estamos ocasionalmente e com os quais não temos grande confiança. Por sua vez, os familiares mais próximos estarão, quase sempre, nos laços fortes, pois com esses mantemos laços afetivos e relacionais fortes.

Procure-se, agora, perceber por que razão Granovetter entendeu que os laços fracos eram mais susceptíveis de providenciar oportunidades de emprego. A razão prende-se com o facto de os laços fracos permitirem estar presentes em outros meios sociais que não apenas aquele onde o indivíduo se insere, e isto permite ter contacto com outras pessoas e um acesso a uma série de informações a que os laços fortes, mais restritos e que, à partida, se movimentam nos mesmos meios do indivíduo, não acederão, evitando a informação redundante, por exemplo (Granovetter, 1973). Assim sendo, será mais fácil obter essas informações junto desses laços fracos, mesmo que o contacto com eles não se efetue com a quantidade e a regularidade de que beneficiam os laços fortes. Para comprovar a sua tese, Granovetter efetuou alguns estudos. Um desses trabalhos foi publicado em forma de livro e intitulou-se, precisamente, Getting a Job. Examinando 282 empregados de um subúrbio de Boston, Granovetter conseguiu demonstrar que "os contactos informais pessoais eram os meios principais através dos quais os indivíduos tinham encontrado o trabalho" (Piselli, 2002:473). Concluía-se, então, que os indivíduos mudavam de trabalho porque aproveitavam informações importantes através dos seus contactos que, por norma, eram constituídos por pessoas empregadas em trabalhos diferentes dos deles (idem). Note-se, portanto, que o enfoque da teoria de Granovetter é colocada nas informações que os laços fracos permitem fazer chegar ao interessado. 
Mas não foram só os laços fracos, e a sua importância no provimento de recursos, que foram alvo de estudos. Margaret Grieco, no seu livro Keeping in the Family, de 1987, conseguiu demonstrar, por sua vez, que são as relações familiares e de parentesco (laços fortes, portanto) que mais importância assumem no recrutamento para o trabalho (Piselli, 2002:474). Interessa, pois, reter as principais críticas que ela efetua ao trabalho de Granovetter e que se centram, essencialmente, em dois aspetos: a definição de força da relação de Granovetter (baseada na frequência do contacto); e a importância das obrigações recíprocas da relação (saber se a informação dada para conseguir um emprego foi para pagar um favor anterior). No caso das relações de parentesco, defende a autora, essa obrigação de reciprocidade é inata. Granovetter, nos seus estudos, não contempla este tipo de análise, daí a crítica de Grieco, como se pode observar no texto de Fortunata Piselli (2002). Ainda, no mesmo texto, explora-se um elemento fundamental, no qual Grieco se centra e que pode ser determinante para entender a fraqueza do argumento de Granovetter na sua defesa da força dos laços fracos, e que se prende com o facto de o estudo do autor ter sido efetuado relativamente a trabalhos qualificados numa grande cidade americana e numa altura em que se fazia sentir a falta de pessoal qualificado nesse setor. Importa questionar se o sucesso conseguido pelas informações obtidas através dos contatos dos laços fracos seria o mesmo num contexto diferente.

Estudos recentes parecem colocar em causa a validade dessa força, especialmente pela razão de o possuidor da informação ter a possibilidade de optar se quer ou não partilhá-la. Essa divulgação pressupõe que o detentor da informação faça, em primeiro, uma análise da sua rede de contactos, e só quando tem a certeza que a informação, ou recomendação, incidirá num contacto que se ajusta plenamente à vaga, e que não lhe causará, mais tarde, desconforto junto desse empregador por se revelar uma má escolha, é que ele acede em partilhá-la (Marin, 2012). Nesse sentido, o estudo deste investigador conclui que a informação, relativamente a uma oportunidade de emprego que ainda não é pública, será, com maior probabilidade, transmitida a um contacto que, embora laço fraco, esteja no lote das pessoas com as quais o informador tem maior confiança, visto que, mesmo no seio dos laços fracos, a ligação entre os atores pode variar desde a simples comunicação frequente (no caso de serem colegas de trabalho, por exemplo) até relações que denotam já laços de amizade (Hollenbeck \& Jamieson, 2015).

Existe, depois, outro aspeto que importa salientar na problemática que envolve a hipotética força dos laços fracos no provir de informação privilegiada para oportunidades de emprego, e que se prende com o facto de esses laços fracos serem, ao fim e ao cabo, partes interessadas nessa informação, uma vez que os indivíduos que se inscrevem nas redes sociais profissionais fazem-no não com intentos de recreação, como no caso do Facebook, mas sim com o propósito de construírem uma rede de contactos que lhes permitam colher benefícios 
desse conhecimento a qualquer altura. É nesse sentido que importa reter a distinção entre utilizadores ativos e passivos destas redes sociais (Pedroso, 2016), sendo os ativos aqueles que utilizam as redes para procurarem oportunidades de emprego (desempregados, por exemplo) e os passivos os que não o fazem (por estarem empregados), mas que estão disponíveis, quer porque são descobertos na rede, quer porque tomam conhecimento de uma informação relevante, para aproveitar uma nova oferta de emprego que surja, o que os transforma também em potenciais concorrentes do utilizador da rede, especialmente os que atuam numa área profissional coincidente com a dele.

\section{Os Laços Latentes}

Ao procurar analisar o potencial das redes sociais no gerar de capital social, como o LinkedIn, por exemplo, surgem as ideias de bridging e bonding. Se a primeira se associa, por norma, aos laços fracos, já a segunda está normalmente ligada aos laços fortes. Baseado nas teses de Granovetter, entende-se por bridging:

as conexões soltas entre indivíduos que podem providenciar informação útil ou novas perspetivas entre eles, mas normalmente não suporte emocional.

sendo o bonding:

o capital social que pode ser encontrado entre indivíduos que se encontram em relações emocionalmente próximas, tais como as encontradas entre familiares e amigos próximos (Ellison, Steinfield, \& Lampe, 2007:1146, tradução nossa).

Ainda no mesmo texto, verifica-se que Putnam (2000) defende que bonding reflete laços fortes com familiares e amigos íntimos que poderão provir suporte emocional ou facilitar recursos. Retém-se aqui que há formas distintas de lidar com as conexões no sentido de gerar capital social e essas relações variam dependendo quando se trata de laços fortes ou fracos. Poder estabelecer a ligação entre conexões parece ser aqui, no entanto, o ponto fulcral para conseguir boas oportunidades de obter informação valiosa para alcançar objetivos, como a busca de emprego, por exemplo. E, neste particular, o LinkedIn afigura-se como uma ferramenta poderosa para alcançar esse propósito. No caso que aqui abordaremos, apenas 103 conexões permitem ao utilizador conectar-se a 13.004.104 pessoas ${ }^{3}$.

\footnotetext{
3 A versão gratuita do LinkedIn deixou de permitir o acesso a informação aos contactos de grau 3 (contactos associados aos nossos contactos), sendo atualmente necessário ter uma conta paga para o conseguir. Contudo, numa análise feita em Agosto de 2018 à conta utilizada para este trabalho (para uma primeira versão deste artigo), foi obtida a informação que a rede estaria ligada a 13.004.104 de contactos de grau 3.
} 
Recorrendo ao conceito de laços latentes (Haythornthwaite, 2011), eles são os laços que existem, mas não estão ainda ativados, o que, quando transportado para uma comunidade como o LinkedIn, por exemplo, representa os laços das redes sociais que são tecnicamente possíveis, mas socialmente não estão ainda ativados (Ellison et al., 2007:1162). A vantagem de uma rede social é poder transformar laços latentes em laços fracos e, à luz das ideias de Granovetter, o utilizador poder daí retirar benefícios.

No exemplo do LinkedIn aqui tratado, pretende-se, agora, fazer uma outra abordagem, que se prende com a possibilidade de descobrir e ativar laços latentes, existentes, mas ainda desconhecidos. Fala-se em descobrir, porque, mais do que entender os laços latentes como ligações adormecidas, poderia ter mais interesse entendê-los como ligações que poderão vir a ser feitas (pontes que poderão ser construídas), mas que ainda não estão descobertas. No caso do LinkedIn há a possibilidade de fazer pesquisas detalhadas de profissionais de qualquer empresa ou área que se pretenda. Se um determinado utilizador, por exemplo, pretender pesquisar quem é o responsável pelo recrutamento de uma empresa pode fazê-lo através das ferramentas que o sítio lhe coloca à disposição. O LinkedIn dará, desde que esse registo exista, a informação de quem é a pessoa em questão. Por si só, esta informação já seria interessante, no sentido de perceber quem é a pessoa com quem interessa falar para conseguir uma oportunidade em determinada empresa. Mais importante do que isso, no entanto, é a funcionalidade que esta rede social permite em apresentar quais as conexões do utilizador que já estão associadas à pessoa em questão. Esta ferramenta parece, de facto, revestir-se de particular importância, porquanto pode suceder que determinado contacto do utilizador possa estar relacionado com um profissional como o que é pesquisado e ser o LinkedIn a permitir chegar a essa informação, que de outra forma poderia nunca ser revelada nos contactos entre estas duas pessoas. Pode entender-se isto como sendo um laço latente, isto é, um laço que existe, mas não foi ainda ativado, por não ter sido ainda descoberto pela parte mais interessada. Neste particular, o LinkedIn providencia um auxílio importante no desbloquear desta dificuldade.

Há outro aspeto a salientar na forma como esta rede é programada e que está associada à teoria dos seis degraus de separação entre duas pessoas de Stanley Milgram (1967): o LinkedIn classifica as conexões por graus de separação do utilizador, ou seja, classifica como sendo de grau 1 as conexões pedidas ou aprovadas pelo utilizador; de grau 2 as ligações dos seus contactos; e de grau 3 os utilizadores associados aos utilizadores do tipo 2. É desta forma que o LinkedIn, de facto, consegue, pelo menos em teoria, colocar alguém em contacto praticamente com toda a gente que lhe possa interessar. No caso da nossa página pessoal do LinkedIn, eram apresentados 13.004.104 contactos de grau 3, (todas aquelas que de alguma forma podem ser acedidas através de contactos de contactos). Imagine-se a imensidade de laços latentes que existe à espera de ser ativados. 
Resta, por último, perceber como é que ativando esses laços e transformando-os de latentes em fracos se poderá rentabilizar essa nova ligação em termos de gerar capital social. Essa é uma das questões que não encontrará resposta neste texto, mas que poderia ser interessante investigar em futuros trabalhos.

\section{Metodologia}

Com este exercício quisemos perceber se ter uma conta no LinkedIn aumentaria, de facto, o nosso capital social na procura de nova colocação profissional. Nesse sentido, decidimos analisar os nossos contactos na rede, tendo em vista a aparente ligação entre o capital social e a força dos laços fracos na busca de emprego. A plataforma não nos permite saber se a relação que determinado contacto mantém com o utilizador da rede se afigura como sendo um laço fraco ou forte. Por essa razão, esta experiência restringiu-se à análise de uma única conta (a nossa), pois seria a única forma de podermos saber qual a força dos laços dos utilizadores analisados, o que limitou imenso este exercício e impediu que a abordagem à plataforma pudesse ser mais abrangente, elemento essencial para procurar confirmar ou infirmar representatividade para o problema aqui discutido.

Recorrendo às opções de pesquisa disponibilizadas pela versão gratuita do LinkedIn, a nossa análise centrou-se na quantificação e tipificação da nossa rede de contactos. Dessa forma, começámos por contabilizar o número de contactos de nível 1 (os que foram por nós convidados ou que nos solicitaram serem acrescentados) e perceber a quantos contactos de nível 2 (contactos dos nossos contactos) eles se ligam. Filtrámos os contactos por atividade profissional com base na informação que cada um coloca no seu perfil de apresentação. Recorremos, ainda, ao filtro de localização, para encontrar os contactos que pertenciam à nossa área geográfica, uma vez que eles podiam constituir-se como potenciais candidatos a ofertas de vagas de emprego que pudessem surgir.

Com base nas informações recolhidas, procurou avaliar-se de que tipo de laços é composta uma rede de LinkedIn; verificar qual a diversidade em termos profissionais existente; qual a distribuição geográfica dos contactos e a sua posição perante o emprego, para podermos confirmar, ou não, se aqueles contactos constituem um recurso valioso para contribuir para aumentar o capital social do utilizador.

\section{Resultados}

Analisada a conta do LinkedIn (Quadro I), conclui-se que ela é composta por 106 conexões de grau 1 (apenas contactos convidados para a rede ou que nos convidaram) e 73151 de grau 2 (contactos dos nossos contactos). As ligações 
existentes podem ser classificadas como sendo laços fracos: antigos colegas de trabalho ou conhecidos, muitos da mesma área profissional, com os quais se mantém contacto esporádico, mais por via electrónica do que presencial. Das 106 conexões existentes, 49 são de antigos colegas de profissão (46\%), 57 pertencem a utilizadores que, embora inserindo-se noutra atividade profissional, atuam dentro da mesma área profissional, como sucede com 18 deles, o que totaliza 67 contactos em 106 (63\%). Quando circunscrevemos a análise por área geográfica, concluímos que 51 contactos (48\%) atuam na mesma zona do utilizador da conta analisada, 35 deles no mesmo ramo de atividade (69\%).

Quadro 1. Caracterização da Rede LinkedIn

\begin{tabular}{|lrr|}
\hline & \multicolumn{2}{c|}{ Caracterização Rede } \\
& Grau 1 & Grau 2 \\
Contactos & 106 & 73151 \\
& & \\
& \multicolumn{1}{c}{ Área Profissional $(\mathrm{n}=106)$} \\
Mesma & & $67(63 \%)$ \\
Outra & $39(37 \%)$ \\
& & \\
Mesma & Zona Trabalho $(\mathrm{n}=51)$ \\
Outra & $35(69 \%)$ \\
& & $16(31 \%)$ \\
\hline
\end{tabular}

Fonte: Elaboração própria.

Ora, à luz das teses de Granovetter, esta rede poderia ser uma excelente via de obtenção de informações para um novo emprego, pois é composta por laços fracos, distribuídos por uma zona geográfica coincidente com a do utilizador e atuando na mesma atividade. Mas quando se procura analisar a relevância destes laços para obtenção de informação importante para um novo emprego, o facto de a maior parte dos integrantes da rede serem profissionais que atuam no mesmo mercado pode tornar a informação redundante, por um lado, e funcionar como desincentivo para a sua partilha, por outro, uma vez que este profissional (ativo ou passivo do LinkedIn) não descurará uma oportunidade de mudança para outra empresa mais estável ou de mais sólida reputação, pelo que poderá tender a não querer partilhar a informação sobre uma oportunidade de emprego da qual entretanto possa vir a tomar conhecimento.

\section{Discussão}

Verifica-se nesta rede um padrão de conexões essencialmente relacionadas com a mesma atividade profissional e que pode concorrer para as mesmas oportunidades de emprego. Tal como Grieco (1987) salientou no seu trabalho, também aqui a questão do tempo e do local têm importância, pois, numa altura de 
escassez de empregos, sobram sempre candidatos relativamente às oportunidades que surgem. Na crítica que a autora fazia a Granovetter, explorava-se precisamente esta questão, isto é, o facto de o estudo do investigador se centrar num tipo de profissionais numa altura e num local específicos onde havia escassez dessa mão-de-obra qualificada, o que, portanto, facilitaria a colocação da amostra no mercado de trabalho. Não se pretende com isto desvalorizar o estudo de Granovetter, que foi reconhecido e cujas teses foram, inclusivamente, validadas e confirmadas posteriormente por outros investigadores, como é o caso de Nan Lin (2004). No entanto, e relativamente às ideias defendidas por Granovetter, alguns aspetos podem levantar questões, como sejam os critérios utilizados para estabelecer a força dos laços, que se baseiam, em grande medida, no tempo passado junto (Piselli, 2002:474). Por outro lado, neste tipo de laços existirá, a priori, uma menor confiança entre os diversos atores, e este aspeto poderá ser determinante para que se queira, ou não, ajudar alguém na busca de emprego (Marin, 2012). Ao ter em conta, como acontece hoje, que os profissionais se movimentam em mercados muito saturados e com poucas oportunidades de emprego, não terá a confiança um papel fundamental para que alguém aceda em facultar informação importante para que outro consiga uma colocação? Tendo em consideração esta questão, não será, depois, lícito questionar até que ponto estes laços fracos presentes nestas redes depositarão, efetivamente, a confiança necessária nos seus conhecidos, para neles apostarem como possíveis candidatos para um lugar que lhes é comunicado por alguém? Qual será o papel dos laços fortes neste particular? Não poderá suceder que se dê primazia às relações mais próximas para providenciar informação útil na busca de emprego?

Ao contrário do que acontece no setor público, onde a rede de contactos parece não ter influência na obtenção de emprego, uma vez que são as habilitações do candidato que mais contam para ser bem-sucedido no concurso (Chua, 2011), no setor privado os contactos, especialmente por via da informação facultada em primeira mão ou através de uma recomendação pessoal junto do empregador, podem fazer a diferença. Mas, para que tal aconteça, é necessário que quem possui a informação se sinta motivado para a partilhar, e, no caso de mercados saturados e com poucas oportunidades de trabalho, isso pode ser dificultado, quer porque essa informação fica reservada para contactos que lhe estão mais próximos, quer porque ele a reserva para seu próprio benefício. A confiança assume um papel fundamental no gerar de capital social, como foi observado num estudo feito numa pequena aldeia portuguesa que pretendia encontrar respostas para a dificuldade em esta gerar capital social, e onde a falta de confiança foi, precisamente, responsabilizada por essa dificuldade (Carmo, 2008).

É certo que o caso aqui analisado não pode servir tão pouco de amostra para tirar conclusões relativamente à matéria tratada. Ainda assim, este exemplo poderá servir como ponto de partida para uma reflexão que 
tenha em mente a eficácia de redes do tipo das do LinkedIn para a obtenção de emprego, especificamente através da eventual mais-valia que o capital social dos seus laços possa gerar na obtenção de informação privilegiada. A própria página do LinkedIn apresenta como casos de sucesso recrutamentos efetuados por empresas, não fazendo o mesmo com casos de utilizadores que tenham conseguido encontrar emprego com recurso à informação obtida através dos contactos da sua rede. Tendo em conta os seus mais de 560 milhões de utilizadores, não seria expectável que pudessem ser divulgados largos milhares desses casos de sucesso? A verdadeira força dos laços fracos com vista à obtenção de emprego parece, portanto, não ser assim tão visível.

\section{Conclusão}

Neste texto aborda-se a questão do capital social gerado pelas redes sociais na busca de oportunidades de emprego, incidindo essa análise especificamente numa popular rede social para profissionais - o LinkedIn. Começando por compreender o que se entende por rede social e capital social, e de que forma estes conceitos se relacionam, tentou perceber-se em que medida o LinkedIn pode funcionar como um veículo para gerar capital social com vista à busca de emprego, um dos seus objetivos.

A teoria da força dos laços fracos de Granovetter tem sido contestada por estudos como o de Grieco (1987), ao qual Piselli (2002) alude, e que procuram provar algumas fragilidades desta teoria. Na mesma linha de pensamento, a análise às conexões da nossa rede de contactos do LinkedIn permite, pelo menos, questionar a força dos laços fracos como gerador de capital social para a busca de emprego, especialmente quando observamos que a grande maioria, embora seja utilizadora passiva da rede, acaba por ser concorrente, uma vez que atua dentro da mesma área profissional. Contudo, redes como o LinkedIn permitem, com poucas ligações, aceder a milhões de contactos que se poderão revelar como laços latentes à espera de serem ativados. Nesse sentido, e em linha com a teoria dos seis degraus de Milgram, esta plataforma permitirá ligar o utilizador a qualquer pessoa no mundo, permitindo-lhe aceder a contactos decisivos para uma nova oportunidade de emprego. No entanto, as vantagens parecem residir mais na informação que o utilizador pode obter através da sua presença no LinkedIn do que propriamente na informação ou recomendação que um seu contacto lhe possa transmitir ou fazer, pelo que o capital social destes laços fracos reside mais no poder pedir alguma coisa, do que no ser-lhe dado alguma coisa por parte desses contactos. Desta forma, e tendo em conta a possibilidade que estas redes permitem em aceder a pessoas que ainda não conhecemos, mas que podem constituir-se como elementos importantes para conseguir novo emprego, a força dos laços fracos parece residir, afinal, nos laços latentes. 


\section{Referências bibliográficas}

ADLER, P. S., \& KWON, S.-W. (2002), “Social Capital: prospects for a new concept”. Academy of Manegement Review, 27(1), 17-40.

BOURDIEU, P. (1986), The forms of capital. in J. Richardson (org.), Handbook of Theory and Research for the Sociology of Education, Greenwood, 241-258.

CARO, R. M. do. (2008), “A Dificuldade Em Gerar Capital Social”, RURIS - Revista do Centro de Estudos Rurais, 2(2), 159-180.

CHUA, V. (2011), "Social networks and labour market outcomes in a meritocracy", Social Networks, 33(1), 1-11.

ELLISON, N. B., STEINFIELD, C., \& LAMPE, C. (2007), "The Benefits of Facebook "Friends:" Social Capital and College Students' Use of Online Social Network Sites", Journal of Computer-Mediated Communication, 12(4), 1143-1168.

GIRARD, A., \& FALLERY, B. (2011), “E-recruitement : From Transaction-Based Practices to Relationship-Based Approaches", Advanced Series in Management, 143-158.

GOMES, A. F. P. (2011), Recrutamento nas Redes Sociais On-line, ISEG-Instituto Superior de Economia e Gestão.

GRANOVETTER, M. S. (1973), “The Strength of Weak Ties”, American Journal of Sociology, 78(6), 1360-1380.

HAYTHORNTHWAITE, C. (2011), "Social Networks and Internet Connectivity Effects", Information, Communication \& Society, (May 2013), 37-41.

HOLlENBECK, J. R., \& JAMIESON, B. B. (2015), "Human Capital, Social Capital, and Network Analysis: Implications for Strategic Human Resource Management”, Academy of Management Perspectives, 29(3), 370-385.

Jobvite. (2019), Jobvite Recruiter Nation Survey 2018, disponível em: https:/www.jobvite.com/ wp-content/uploads/2018/11/2018-Recruiter-Nation-Study.pdf, consultado em 23 Junho 2019

KOCH, T., GERBER, C., \& KLERK, J. J. De. (2018), “The impact of social media on recruitment : Are you LinkedIn ?”, SA Journal of Human Resource Management, 16(0), 1-14.

LIN, N. (2004), Social Capital A Theory of Social Structure and Action. Cambridge, Cambridge University Press.

LinkedIn (2019), Sobre o LinkedIn, disponível em: https://about.linkedin.com/pt-br?trk=homepage-basic_directory, consultado em 24 de Junho de 2019.

MARIN, A. (2012), “Don't mention it: Why people don't share job information, when they do, and why it matters", Social Networks, 34(2), 181-192.

MILGRAM, S. (1967), “The Small-world problem”, Psychology Today, 1(1), 61-67.

PEDROSO, R. C. (2016), "Redes Sociais e Recrutamento”, Católica Porto Business School.

PENA-LÓPEZ, J. A., \& SÁNCHEZ-SANTOS, J. M. (2017), "Individual social capital: Accessibility and mobilization of resources embedded in social networks", Social Networks, 49, 1-11.

PHULARI, S. S., KHAMITKAR, S. D., DESHMUKH, N. K., BHALCHANDRA, P. U., LOKHANDE, S. N., \& SHINDE, A. R. (2010), "Understanding Formulation of Social Capital in Online Social Network Sites (SNS)", IJCSI International Journal of Computer Science Issues, Vol. 7, Issue 1, No. 3, 92-96

PISELLI, F. (2002), “A Network Analysis nos Estudos sobre a Família: teorias e aplicações”, Revista Contrapontos 3(3), 459-481.

PORTUGAL, S. (2006), "Quanto vale o capital social? O papel das redes informais na provisão de recursos”, in P. H. M. B. Fontes (org.), Redes, Práticas Associativas e Gestão Pública, Recife, Editora da UFPE, 51-74. 
RECUERO, R. da C. (2005), "Um estudo do capital social gerado a partir de redes sociais no Orkut e nos Weblogs", Revista FAMECOS, 12(28), 88-102

RECUERO, R.da C.(2006), “Dinâmicas de Redes Sociais No Orkute Capital Social”, Razónypalabra, volume (52), disponível em: https://dialnet.unirioja.es/servlet/articulo?codigo=2162410, consultado em: 03-07-2019

UTZ, S. (2016), "Is LinkedIn making you more successful? The informational benefits derived from public social media”, New Media and Society, 18(11), 2685-2702. 